\title{
Subjective Well-Being and Social Capital in Belgian Communities. The Impact of Community Characteristics on Subjective Well-Being Indicators in Belgium
}

\author{
Marc Hooghe • Bram Vanhoutte
}

Accepted: 8 March 2010/Published online: 21 March 2010

(C) Springer Science+Business Media B.V. 2010

\begin{abstract}
In this article, we investigate the effect of individual and community level characteristics on subjective well-being in Belgium. Various indicators for subjective wellbeing are being used in a multilevel analysis of the 2009 SCIF survey $(n=2,080)$ and the 2006 Belgian ESS sample $(n=1,798)$. On the individual level, most hypotheses on the determinants of subjective well-being were confirmed. Living with a partner and age were shown to have strong effects, but also social capital indicators had a significant positive effect on subjective well-being. All these effects remained significant controlling for optimism. On the community level, especially unemployment rate had a negative impact on subjective well-being. The analysis further demonstrates that in homogeneous regions, community characteristics have a far weaker impact on subjective well-being indicators than in economically more heterogeneous regions.
\end{abstract}

Keywords Subjective well-being - Community characteristics · Belgium · Multi-level research · Social indicators Flanders · European social survey

\section{Introduction}

While it can be safely assumed that subjective well-being is determined mainly by individual characteristics (DeNeve and Cooper 1998), research has also confirmed the impact of community characteristics on well-being (Farrell et al. 2004). The expectation is that specific features of communities or neighborhoods will have an impact on the quality of life of citizens, even controlling for individual background characteristics (Rahn and Yoon 2009). Recent comparative research suggests that the context of an individual accounts for a substantive part of his or her happiness level (Frey and Stutzer 2000, 2002; Helliwell 2003; Helliwell and Putnam 2004). Societies show strong and persistent differences with regard to their average level of subjective well-being and it is a reasonable expectation that these differences cannot be attributed exclusively to individual psychological differences

M. Hooghe $(\bowtie) \cdot$ B. Vanhoutte

Leuven, Belgium

e-mail: Marc.Hooghe@soc.kuleuven.be 
(Diener et al. 2003; Christoph and Noll 2003). Less is known, however, about which specific community characteristics could have an impact on subjective well-being. Since most of the currently available studies tend to focus on explaining differences between countries, relatively little attention has been given to the neighborhood or community level (Helliwell 2003). Of the studies that are available on the community level, most are based in the US (Fernandez and Kulik 1981; Subramanian et al. 2005) and we have access to few studies from a European context.

In this article we report on the distribution of subjective well-being in Belgian communities. The Belgian case is theoretically relevant because, together with the Scandinavian countries, Belgium is one of the countries in the world with the lowest level of income inequality (OECD 2009). While previously it has been demonstrated that community characteristics matter in highly unequal and/or segregated societies, it remains to be ascertained whether community effects can also be detected in more equal and less segregated societies like Belgium. To answer this research question, we will rely on two different datasets. The first one, Social Cohesion Indicators in Flanders (SCIF), has as main advantage that it includes a full battery of questions on subjective well-being and this allows us to cover various dimensions of well-being. The disadvantage, however, is that it only contains data on the Northern and economically rather homogeneous region of Flanders. The Belgian sample of the European Social Survey-2006, on the other hand offers a less extensive measurement of subjective well-being, but it includes the entire country, thus offering more variance in the independent individual and community level variables. The combination of both datasets, therefore, allows us to solve our research questions in a comprehensive manner.

\section{Subjective Well-Being}

In recent years, subjective well-being has received increasing attention within social sciences in general and more specifically within community studies (Noll 2002; Helliwell 2003). Subjective well-being is usually considered as "a broad category of phenomena that include people's emotional responses, domain satisfactions and global judgments of life satisfaction" (Diener et al. 1999, 277). While positive or negative affects, such as moods and emotions, can be regarded as short-term indicators of subjective well-being, satisfaction with life or with specific domains of life reflects a more cognitive and long term evaluation (Lucas et al. 1996). Increasing life satisfaction or subjective well-being, can be regarded as a paramount striving throughout human history. On a collective level, democratic political systems ideally try to achieve the highest level of life satisfaction for most citizens. On an individual level, people achieve happiness or satisfaction through self realization on a number of life domains, such as work, family, social life, etc. This means that well-being depends not only on individual abilities, or social position, but that it is also dependent on the context, on the 'goodness of others', as Nussbaum (2001) phrased it.

Previous research has demonstrated that well-being data can be used to compare the quality of life between countries. Subjective well-being therefore can be used as an indicator to monitor policies aimed at improving well-being at a national level (Diener 2000; Helliwell 2003). Although historical, religious and cultural differences play an important role in the explanations offered, a significant share of the observed cross-cultural differences can be explained in terms of socio-demographics, community integration and material wealth, although some recent studies have also questioned the cross-cultural measurement equivalence of these scales (Eckersley 2009). 
Not just the national level has been investigated with regard to variations in well-being, but also the local or community level. Some studies find significant differences between communities and regions within a country, as is the case in Switzerland (Frey and Stutzer 2000, 2002), Italy (Rampichini and Schifini d'Andrea 1998) or the US (Fernandez and Kulik 1981; Bjørnskov 2008). Frey and Stutzer (2000), e.g., demonstrate that the presence of procedures for direct democracy and the degree of decentralization of political institutions have a positive impact on the subjective well-being of residents. Not all studies, however, confirm these local differences. For the United Kingdom, Duncan et al. (1995) did not discover any significant community differences with regard to mental health, controlled for composition of the population in those communities. Research in the US (Plaut et al. 2002), too, fails to reveal significant community determinants for general life satisfaction.

While previous research has shown strong inter-state and regional variations with regard to happiness (Bjørnskov 2008), countries appear to be more homogeneous with regard to general life satisfaction (Plaut et al. 2002; Cummins 1995). This might imply that life satisfaction is partly dependent on cultural mechanisms, and we can assume these cultural traits to be present throughout society, no matter what the specific community characteristics might be. Life satisfaction apparently is not just a mechanical sum scale, summarizing one's self-realization in various life domains. It can be considered as part of a cultural process of interpretation and giving meaning to one's life, and we can assume that this process is present throughout society without too much local variation within that society. Individualism, the quintessential feature of the American value system (Bellah et al. 1985), implies that realizing one's well-being is a personal responsibility, since everyone is responsible for his/her own happiness (Suh 2000). Admitting in a survey that one is not satisfied with life in an individualistic culture implies that one has not been able to maximize his/her opportunities, talents and capabilities. Within these cultures one can therefore observe a strong social pressure to evaluate life satisfaction in a positive manner. Comparative research convincingly illustrates that individualism is a substantial part of the explanation of subjective well-being (Diener et al. 1995). There is some disagreement in the literature, however, on the precise causal mechanism to explain the positive relation between individualism and subjective well-being. Inglehart (1997) and others have noted that a cultural climate of individualism creates more opportunities for self-realization, thus enhancing the satisfaction with life among the citizens of these communities.

The current state of the literature, therefore, leads to a number of clear research questions. While local communities apparently have an impact on happiness levels, this is not necessarily the case for subjective well-being. Subjective well-being indicators are strongly influenced by national-level determinants (culture, income level, ...) but it remains to be investigated what kind of community levels can have an impact on subjective well-being. In this article, we therefore will investigate the impact of community level characteristics on subjective well-being, controlling for individual level determinants and for composition effects.

\section{Determinants of Subjective Well-Being}

Given the current literature, it can be expected that both individual characteristics and community level characteristics will have an impact on subjective well-being. These determinants will be briefly reviewed in this section. We start with individual level determinants. 


\subsection{Age, Gender and Family Structure}

In most studies on subjective well-being, gender does not play a significant role. Age on the other hand seems to have a curvilinear effect: both the youngest and oldest age groups have a significantly higher level of well-being with the lowest levels being recorded among the middle age group (Clark and Oswald 1994; Blanchflower and Oswald 2007). Research shows that being married contributes significantly to the level of subjective well-being while being divorced, widowed or separated have an equally clear negative impact (Lucas et al. 2003; Clark and Oswald 1994). Having children, too, seems to have a negative impact on one's level of well-being (Clark and Oswald 1994). Few studies, however, investigate in a systematic manner the interaction effects between these variables.

\subsection{Material Conditions}

Looking at the correlates between material conditions and subjective well-being, one can discern two related patterns. On the one hand, income is positively related to subjective well-being but more recent research shows that material well-being has only a modest effect on subjective well-being (Diener and Oishi 2000; Diener and Biswas-Diener 2002). Furthermore it seems that the relative income level, or the comparison between one's own income and the national average income, has a stronger effect on subjective well-being than the absolute income level (Easterlin 1974, 1995). Furthermore, being unemployed is a strong determinant for a lower level of well-being. The negative effect of unemployment by far surpasses the effect of income loss (Clark and Oswald 1994; Di Tella et al. 2001; Frey and Stutzer 2000; Oswald 1997; Kahneman and Krueger 2006). These findings illustrate that being employed is much more than just earning an income, it can be seen a fundamental part of the self-realization that is the key to subjective well-being.

\subsection{Social Capital}

Social capital, as it is used frequently in contemporary social science, refers to the impact of networks on society and individuals (Putnam 1993, 2000). Apart from having a direct influence on the people included in networks themselves, social networks also have an indirect impact on society in general (Helliwell and Putnam 2004). Both formal networks, through jobs and participation in organizations, and informal networks between friends and neighbors, are supposed to have a positive influence on community life. Next to these more structural features of social capital, the concept contains a more attitudinal component as well: generalized trust. This can be conceptualized as the degree to which one believes people are trustworthy in general, and this attitude has been shown to be cross-culturally equivalent (Reeskens and Hooghe 2008). It is expected that social capital, operationalized either through measures of the degree of participation in formal and informal networks or through trust in others, will have a positive influence on subjective well-being (Helliwell and Putnam 2004). Although research on the relation between social capital and subjective well-being is quite scarce the idea that inclusion in society and social support matters is well documented in research on well-being (Helliwell and Putnam 2004; Winkelmann 2009).

\subsection{Personality Structure}

It is important to point out that happiness, or life satisfaction, cannot be reduced to a personality trait, as has been convincingly illustrated by Veenhoven (1994). Taking 
personality traits into account, however, allows for a more reliable assessment of the impact of demographics, social structure and economical situation on subjective well-being (Hayes and Joseph 2003). Previous research has shown that higher subjective well-being is associated especially with lower levels of neuroticism and higher levels of extraversion (Gutierrez et al. 2005). The tendency to have an optimistic outlook on life obviously has a positive effect on the evaluation of life, regardless of specific circumstances (Veenhoven 1994). Furthermore research on the relation between optimism and subjective well-being indicates significant positive correlations (Wrosch and Scheier 2003). Taking optimism into account, therefore, allows us to assess the relevance of both subjective and objective factors on well-being in a more reliable manner.

\subsection{Community Level Determinants}

Next to all these individual level explanations, we expect that the context in which people live will also influence their level of well-being. Previous research has indicated that unemployment levels (Oswald 1997), income levels (Clark and Oswald 1994), crime rates (Dolan et al. 2008), openness of political institutions (Frey and Stutzer 2000) and ethnic diversity within the community (Putnam 2007; Hooghe et al. 2009a) are expected to play a role in this regard. The assumption is that subjective well-being will be lower in deprived communities with high levels of unemployment and crime. Authoritarian political institutions too, are thought to have a depressing impact on the level of subjective well-being. It is important in this regard to make a distinction between compositional effects and community-level effects. Almost self-evidently, average levels of well-being will be lower in deprived communities. The assumption, however, is that even controlling for one's own level of income, or one's own experience with unemployment, community level indicators of crime, unemployment and income will still have an impact on individual well-being.

\section{Hypotheses}

Thus, far, most research focuses on either psychological or social correlates of well-being. Although it has been stated that the context people live in might affect their subjective well-being this has not been tested extensively in a European context. Therefore, a number of complementary hypotheses are developed:

H1 We expect that living with a partner, having a high income and being employed will have a positive effect on subjective well-being

H2 Social connectedness and generalized trust will have a positive influence on subjective well-being

H3 Unemployment and crime in one's community will have a negative impact on subjective well-being

\section{Data and Methods}

These hypotheses will be investigated using data from the Social Cohesion Indicators Flanders (SCIF) Survey and the third wave of the European Social Survey (ESS) for Belgium. While both of these data sources have some shortcomings from the perspective of 
our study, combined they do allows us to solve all of our research questions. The SCIF survey is a representative survey of respondents in Flanders between 18 and 85 years old. Flanders is the northern autonomous region of Flanders, with 6,162,000 inhabitants or 58\% of the total Belgian population. A face-to-face interview methodology was chosen since this method of interview allows for longer interviews and more reliable answers on complicated measurement instruments. In total, 2,080 respondents participated in the survey. The interviews were carried out between April and July 2009. Respondents were sampled in such a manner that the resulting set is ideally suited for the purpose of multilevel research, with on average 52 respondents in each of the 40 sampled communities (Hooghe et al. 2009b). The Flanders region, however, is rather homogeneous with typically low unemployment levels. Therefore, we will also rely on the Belgian sample within the European Social Survey 2006. The survey contains information on 1,798 respondents, of which $63 \%$ live in the Flemish region, 32\% live in the Walloon region and 5\% live in Brussels (Jowell et al. 2007; Huppert et al. 2009). Data were geo-coded, so that for the ESS respondents too, we could link respondents to specific community characteristics. ${ }^{1}$ Although the ESS questionnaire only included information on 'general well-being', this study covers a broader territory than the SCIF data, as unemployment levels are markedly higher in the Brussels and Walloon regions of Belgium. Both data sets allow us to make a link between individual scores and community level indicators. Belgium is divided in 589 municipalities, with a high degree of autonomy. Municipalities on average have 17,000 inhabitants, so they can still be considered as real communities for most of the population.

\subsection{Subjective Well-Being}

The fact that we have to use two different data sets, leads to the use of different operationalizations of subjective well-being measurements. The dependent variable in the analysis is first of all the subjective well-being of respondents. Research has shown that using multiple indicators of life satisfaction leads to more reliable results than a single question on global life satisfaction (Kahneman and Krueger 2006). In constructing the SCIF questionnaire we closely followed the Cummins (1995) approach to arrive at a valid measurement of subjective well-being. This implies that respondents were asked to rate several life domains on a scale from 0 to 10 (low to high satisfaction). Items included in the SCIF questionnaire were, next to a global measure, satisfaction with health, leisure time, family life, social life, sexual life, the way democracy works and the kind of society we live in (Table 1). It is clear that the last two items measure a different kind of satisfaction, which is reflected in the fact that they constitute a different factor. From this scale, we therefore derive two main dependent variables: individual subjective well-being (with the items referring to the individual situation) and social subjective well-being (with the items referring to society as a whole). Given the strong factor loadings of the items, an analysis on individual items did not prove to be meaningful as this would not lead to additional information. While the various items can be distinguished theoretically, the empirical analysis shows quite convincingly that they refer to a single latent concept. Both subjective well-being scales will be used as dependent variable in the first step of the analysis (based on the SCIF data for the Flemish region). Subsequently, a more limited measurement of subjective well-being will have to be used if we expand the analysis to include the whole of Belgium.

\footnotetext{
1 We are very grateful to Geert Loosveldt and Koen Buellens of the Belgian ESS team who have made this information available.
} 
Table 1 Subjective well-being scales in the SCIF survey 2009

\begin{tabular}{llll}
\hline \multicolumn{1}{c}{$\begin{array}{l}\text { Factor loadings } \\
\text { individual subjective } \\
\text { well-being }\end{array}$} & $\begin{array}{l}\text { Factor loadings } \\
\text { social subjective } \\
\text { well-being }\end{array}$ & $\begin{array}{l}\text { Cronbach's } \\
\text { alpha if } \\
\text { deleted }\end{array}$ & $\begin{array}{l}\text { Scale } \\
\text { average } \\
(0-10)\end{array}$ \\
\hline $\begin{array}{l}\text { How satisfied are you with your } \\
\text { life in general? }\end{array}$ & 0.739 & 0.746 & 7.91 \\
$\begin{array}{l}\text { How satisfied are you with your } \\
\text { health? }\end{array}$ & 0.575 & 0.783 & 7.45 \\
$\begin{array}{l}\text { How satisfied are you with your } \\
\text { leisure time? }\end{array}$ & 0.585 & 0.788 & 7.29 \\
$\begin{array}{l}\text { How satisfied are you with your } \\
\text { family life? }\end{array}$ & 0.794 & 0.734 & 8.23 \\
$\begin{array}{l}\text { How satisfied are you with your } \\
\text { social life? }\end{array}$ & 0.784 & 0.734 & 7.77 \\
$\begin{array}{l}\text { How satisfied are you with your } \\
\text { sexual life? }\end{array}$ & 0.703 & 0.765 & 7.29 \\
$\begin{array}{l}\text { How satisfied are you with the } \\
\text { way democracy works in }\end{array}$ & 0.916 & & 5.07 \\
$\quad$ Belgium? \\
$\begin{array}{l}\text { How satisfied are you with the } \\
\text { kind of society we live in? }\end{array}$
\end{tabular}

Principal component analysis of subjective well-being scales. Two factors: $59.47 \%$ explained total variance, Eigenvalues: $3.339,1.419$. Cronbach's alpha: 0.790 and 0.814. Source: SCIF survey 2009, $n=2,079$

The results show that respondents are most satisfied with their family life (an average scores of 8.23), social life and life in general, while there is somewhat less satisfaction with one's leisure time and sexual life. For the social subjective well-being scale, average scores are much lower. Missing values were imputed using the EM method, which was justified since Little's MCAR test was significant at the $p=.000$ level.

\subsection{Individual-Level Variables}

In the analyses, we will control for income, unemployment and household composition, as it is hypothesized that these factors will have an impact on subjective well-being. Income was measured as the household income. In the analysis, the natural logarithm of the equivalent household income is used to normalize the distribution. ${ }^{2}$ Item non-response to the question on family income remained limited to $12 \%$ of all respondents in the SCIF survey and $13 \%$ in the Belgian ESS sample. The mean household income in the sample is 2,837 euro/month in the SCIF data set and 2,711 euro/month in the ESS sample.

Furthermore, we also asked respondents about their professional status. In the SCIF survey this resulted in $53 \%$ of respondents having paid work, $25 \%$ is retired, $8 \%$ are students, $5 \%$ is unemployed and $8 \%$ is at home or not able to work. The relative high number of pensioners in the SCIF sample is due to the fact that sampling continued up to the age of 85 , and the percentage reflects the ageing structure of the population of the Flemish region. For the ESS sample, figures are 50\% paid work, $20 \%$ retired, $10 \%$

\footnotetext{
${ }^{2}$ Hagenaars et al. (1994) have developed the OECD modified household equivalence scale, which takes in account the number of people in a household. Applying this formula did not lead to other results with regard to the effect of family income.
} 
students, $6 \%$ unemployed, and $15 \%$ at home or not able to work. The higher rate of respondents at home or not able to work in ESS is probably due to the higher number of respondents in the 'other' category, which we recoded in this group. Furthermore, we will also control for gender and age. Given the expectation of a U-shaped effect of age, we also include age squared. Since we expect family composition matters for individual wellbeing, we distinguished respondents living with a partner and those living alone, and we also included information on whether there was a child under the age of 16 present in the household.

As indicators for social capital, both structural and attitudinal features are used. Informal social networks are operationalized by the frequency of visits to family, inviting friends at home and visiting concerts and exhibitions, where respondents could answer on a six point scale with categories ranging from never (1) to more than once a week (6). Formal social networks are taken into account by including information on whether the respondent is an active member of voluntary associations or not (dummy variable). In the ESS the frequency of visits to friends and families relies on just one item instead of two, and there is no good measure for active participation in associational life, so this analysis will have to remain less comprehensive.

Finally, we also include generalized trust as it is expected that people who are more trusting will also have a higher level of subjective well-being. Generalized trust was measured by including three questions: 'Generally speaking, would you say that most people can be trusted or that you can't be too careful in dealing with people?', 'Would you say that most of the time people try to be helpful or that they mostly look after themselves?' and 'Do you think most people would try to take advantage of you if they got a chance, or would they try to be fair?'. All three questions form one coherent factor (Eigenvalue 2.01; 66.8\% of explained variance; Cronbach's alpha: 0.74 in SCIF and Eigenvalue $1.85 ; 61.7 \%$ of explained variance; Cronbach's alpha 0.69 in ESS).

Finally a shortened version of the Re-evaluated Life Orientation Test (Scheier et al. 1994), a scale for discursive optimism was included in SCIF. It consists of five items expressing statements such as "I never expect things to turn out positively for me", "In general I expect more good than bad things to happen with me", on which the respondent could answer on a five point scale ranging from 1 (totally disagree) to 5 (totally agree). The scale is one-dimensional, with one dominant factor (Eigenvalue of 2.38, 47.7\% explained variance). The ESS used the original Life Orientation Test (Scheier and Carver 1985), using four similar items, and the same scale for the answers. The Principal Components analysis yields one factor (Eigenvalue of 2.10, 52.4\% explained variance). All individual level variables are presented in Tables 2 and 3.

\subsection{Community-Level Variables}

The aim of this article is to investigate whether community characteristics play a role in determining individual well-being. The literature allows us to assume that subjective wellbeing will be lower in deprived urban regions with high levels of unemployment and crime. Therefore, population density, crime rates and the average income per inhabitant will be used as community level variables (Table 4). Population density was taken from the official population register. Unemployment rates were obtained from the Ministry of Labor, and they are expressed in the percentage of the labor population that is fully unemployed. Violent crime rates, finally, were taken from the statistics of the Belgian federal police. Given the small numbers involved in any single observation year, here we included the average crime rate for the years 2001-2006. Here too, the variation is 
Table 2 Frequencies of individual-level variables for SCIF data (Flemish region)

\begin{tabular}{|c|c|c|c|c|c|}
\hline Variable & Missing & Mean & SD & Minimum & Maximum \\
\hline Individual subjective well-being & 1 & 0 & 1 & -5.33 & 2.34 \\
\hline Social subjective well-being & 1 & 0 & 1 & -3.2683 & 3.120027 \\
\hline General Satisfaction with life (item) & 3 & 7.91 & 1.59 & 0 & 10 \\
\hline Age & 0 & 47.19 & 17.94 & 17 & 84 \\
\hline $\mathrm{Age}^{2}$ & 0 & 2548.34 & 1763.11 & 289 & 7056 \\
\hline Gender $(0=$ men; $1=$ women $)$ & 0 & 0.52 & 0.50 & 0 & 1 \\
\hline Educational level (low) & 0 & 0.28 & 0.45 & 0 & 1 \\
\hline Educational level (high) & 0 & 0.31 & 0.46 & 0 & 1 \\
\hline Family income (ln) & 263 & 7.22 & 0.62 & 1.10 & 10.41 \\
\hline Unemployed & 2 & 0.05 & 0.22 & 0 & 1 \\
\hline At home & 2 & 0.08 & 0.28 & 0 & 1 \\
\hline Retired & 2 & 0.25 & 0.43 & 0 & 1 \\
\hline Student & 2 & 0.08 & 0.27 & 0 & 1 \\
\hline Living with partner & 0 & 0.68 & 0.47 & 0 & 1 \\
\hline Living with child under 16 & 0 & 0.29 & 0.46 & 0 & 1 \\
\hline Generalized trust & 0 & 53.8 & 18.07 & 0 & 100 \\
\hline Frequency of family visits & 2 & 4.26 & 1.38 & 1 & 6 \\
\hline Frequency of inviting friends & 1 & 3.30 & 1.35 & 1 & 6 \\
\hline Frequency of visiting exhibitions, concerts, ... & 1 & 1.86 & 0.89 & 1 & 6 \\
\hline Active membership of organizations & 6 & 0.58 & 0.49 & 0 & 1 \\
\hline Optimism & 0 & 0 & 0.87 & -3.57 & 1.73 \\
\hline
\end{tabular}

Frequencies and characteristics of individual level variables used in the analysis. Source: SCIF survey 2009. Total $n=2,080$

significant, with a range from 4.3 violent crimes per 1,000 inhabitants in the safest community to 28.2 crimes/1,000 inhabitants in the least safe community in Flanders. Contrary to the situation in Switzerland, Belgian municipalities do not differ with regard to their institutional structure, so there was no point in including information about the democratic openness of municipalities (Frey and Stutzer 2000).

\section{Results}

The analysis will proceed in two steps: first a stepwise OLS regression will estimate the impact of the individual level variables on both individual and social subjective well-being. Given the fact that subjective well-being was measured as a principal component, an ordinary least square regression was preferred. Departing from a model that examines the influence of the socio-demographic characteristics and the position in the social structure, we will subsequently add indicators of social capital to the model. In a final step a measure for optimism will be added to the model, so that the relevance of the objective indicators and of social capital can be assessed in a fully controlled manner.

Second, we will take the analysis a step further by investigating the occurrence of local variation in subjective well-being, using both Flemish and Belgian data. We will explain 
Table 3 Frequencies of individual-level variables for ESS data (Belgium)

\begin{tabular}{lcllll}
\hline Variable & Missing & Mean & SD & Minimum & Maximum \\
\hline General satisfaction with life (item) & 3 & 7.409 & 7.409 & 0.000 & 10.000 \\
Age & 0 & 46.194 & 18.643 & 14.417 & 95.333 \\
Age $^{2}$ & 0 & 2481.240 & 1814.746 & 207.840 & 9088.444 \\
Gender (0 = men; 1 = women) & 0 & 0.467 & 0.499 & 0.000 & 1.000 \\
Educational level (low) & 1 & 0.359 & 0.480 & 0.000 & 1.000 \\
Educational level (high) & 1 & 0.278 & 0.448 & 0.000 & 1.000 \\
Family income (ln) & 242 & 7.129 & 0.648 & 3.689 & 9.306 \\
Unemployed & 57 & 0.059 & 0.236 & 0.000 & 1.000 \\
At home & 57 & 0.147 & 0.354 & 0.000 & 1.000 \\
Retired & 57 & 0.200 & 0.400 & 0.000 & 1.000 \\
Student & 57 & 0.096 & 0.295 & 0.000 & 1.000 \\
Living with partner & 6 & 0.641 & 0.480 & 0.000 & 1.000 \\
Living with child under 16 & 6 & 0.390 & 0.488 & 0.000 & 1.000 \\
Generalized trust & 3 & 0.000 & 1.000 & -3.031 & 2.851 \\
Frequency of visiting family and friends & 3 & 5.202 & 1.450 & 1.000 & 7.000 \\
Frequency of participating in local activities & 5 & 2.641 & 1.053 & 1.000 & 5.000 \\
Active membership of organizations & 3 & 7.409 & 7.409 & 0.000 & 10.000 \\
Optimism & 6 & 0.000 & 1.000 & -3.841 & 2.013 \\
\hline Frequencies and & 57900
\end{tabular}

Frequencies and characteristics of individual level variables used in the analysis. Source: SCIF survey 2009. Total $n=1,798$

Table 4 Frequencies of community-level variables

\begin{tabular}{llllll}
\hline & Missing & Mean & SD & Minimum & Maximum \\
\hline Flemish region & & & & & \\
$\quad$ Unemployment rate 2005 & 0 & 7.95 & 2.84 & 4.58 & 15.14 \\
$\quad \begin{array}{l}\text { Population density 2006 } \\
\text { Average violent crime rate 2001-2006 }\end{array}$ & 0 & 587.13 & 483.60 & 121.51 & 2238.38 \\
Belgium as a whole & 12.47 & 5.71 & 4.32 & 28.22 \\
Unemployment rate 2005 & 0 & & & & 3.14 \\
Population density 2005 & 0 & 691.48 & 1813.54 & 22.16 & 20766.73 \\
Average violent crime rate 2001-2006 & 0 & 12.35 & 5.26 & 0.00 & 36.04 \\
\hline
\end{tabular}

Indicators at the community level, obtained from the Ministry of Labor, population statistics and Belgian federal police. $n=589$ municipalities for Belgium, 308 for the Flemish region

this variation by including community level and individual level variables simultaneously in one multilevel regression analysis.

Table 5 presents the results of the OLS regression analysis on individual subjective well-being. The first model shows that gender has no significant effect on individual wellbeing, as was expected. Both age and age-squared are significant, and the quadratic term is positive, therefore the U-shaped relation between age and well-being found in the literature is confirmed with our data. Educational level does not seem to have a significant effect on well-being, controlling for other indicators of position in the social structure. Household 


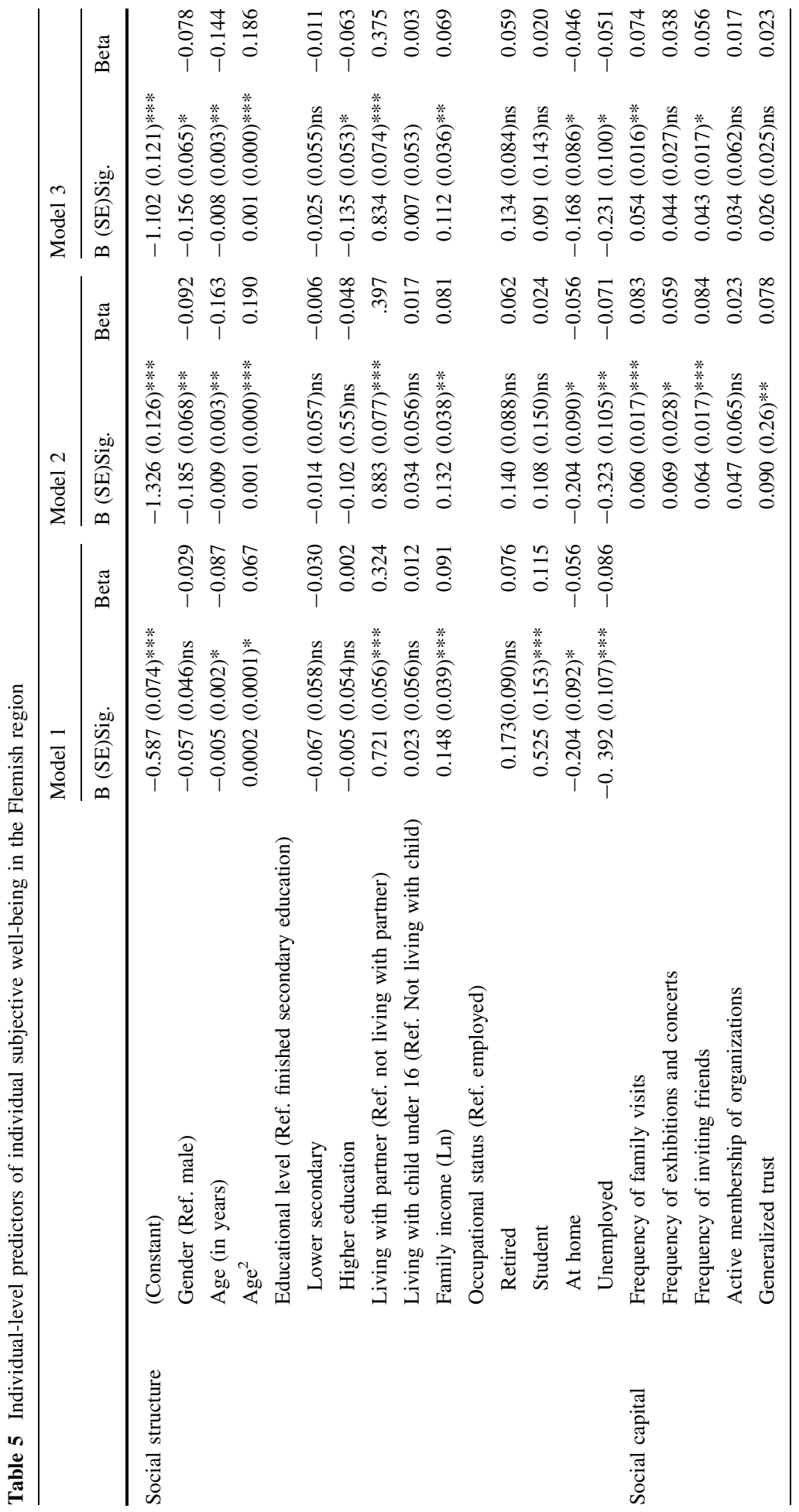




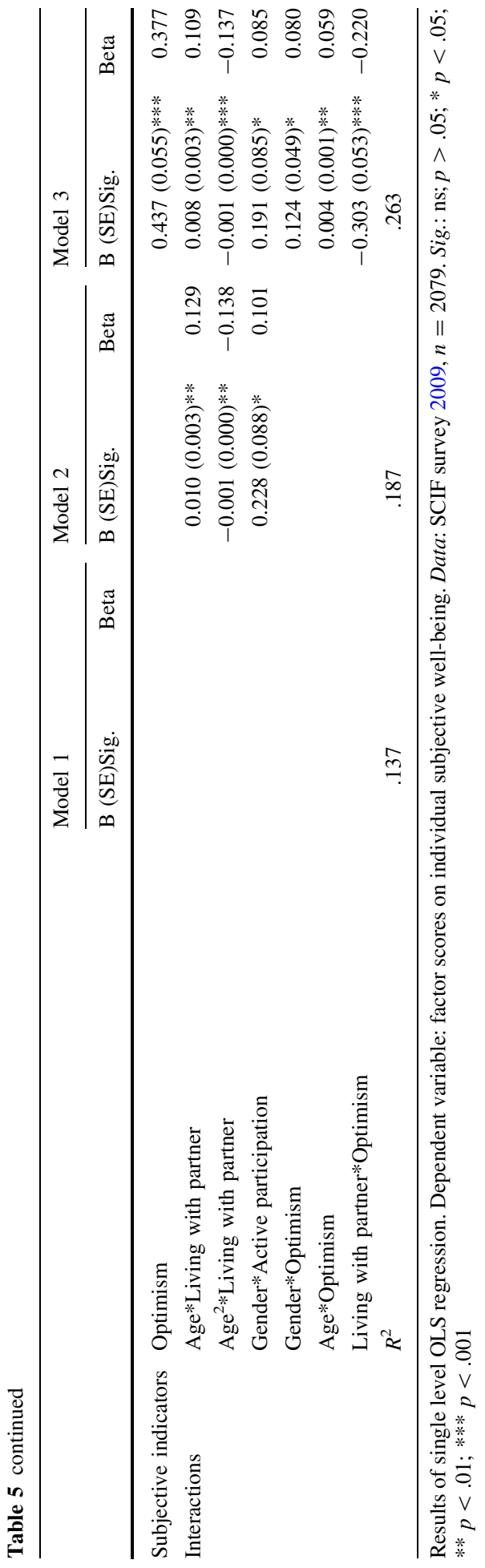


composition yields strong effects: respondents living with their partner are significantly more satisfied with their life. The presence of children, however, does not have a significant effect. The level of the family income has a positive effect on well-being, confirming that economic conditions are a part of the picture, but not the most important one. Looking at occupational status, we can observe that the unemployed and people without a paid job are less satisfied, other factors being equal. It should be noted that being unemployed, controlling for household income, still has a negative influence on subjective wellbeing. This might serve as an indication that having a job is not only important for economic reasons.

In Model 2 indicators of participation in networks and generalized trust are added to the model. The explained variance of the model rises from .14 to .19. All social capital indicators have moderate positive impacts on well-being, underlining the importance of being involved, through active participation in organizations or through participating in cultural life, and of receiving social support, through intensive contacts with family or friends, and of trust in others. A remarkable finding is that active participation in associational life matters especially for women. Including social capital variables in the model weakens somewhat the socio-demographical effects, but in general this module clearly adds to our ability to explain subjective well-being.

Model 3 adds optimism to the model, so we can control for a general propensity of the respondents to have a rosy outlook on all domains of life. Indicators of social background and social capital remain significant, even when controlling for a positive perception of reality. Although optimism in general seems to have a strong correlation with subjective wellbeing, it has an even larger effect for older people and for women. The influence of optimism on well-being for people living with their partner is significantly smaller. The current analysis confirms that living with a partner has a strong effect, both directly and as a result of the interaction effect with age and optimism. In the social capital domain, frequent contact with family seems to have to strongest effect on individual subjective well-being for all respondents. All these findings hold after controlling for optimism.

In Table 6 we turn to the second dimension of subjective well-being, the social subjective well-being or satisfaction with the society one lives in. The results of this analysis are not that impressive. Only age has a meaningful negative influence on satisfaction with society, which remains strong after controlling for social capital and optimism. Generalized trust on the other hand is strongly associated with a higher level of social subjective well-being. Optimism also has a positive relation with social well-being. In total the model offers a modest explanation: younger people, people who trust others more and optimistic people, have a more positive opinion on the state of society. The explained variance of this model, however, remains much lower than for the model on individual subjective wellbeing. The analysis confirms the structural difference between determinants of individual and social subjective well-being, as social subjective well-being can only be explained very partially by individual and community level variables (Table 7).

\section{Multi-Level Analysis}

The previous analysis, of course, was limited to the individual level and it allowed us to determine the most important individual level determinants of subjective well-being. In order to investigate hypothesis 3 we need to take an additional step in the analysis by also including community level indicators. Therefore, a multilevel model is estimated in order to investigate community level influences on subjective well-being. This kind of model 


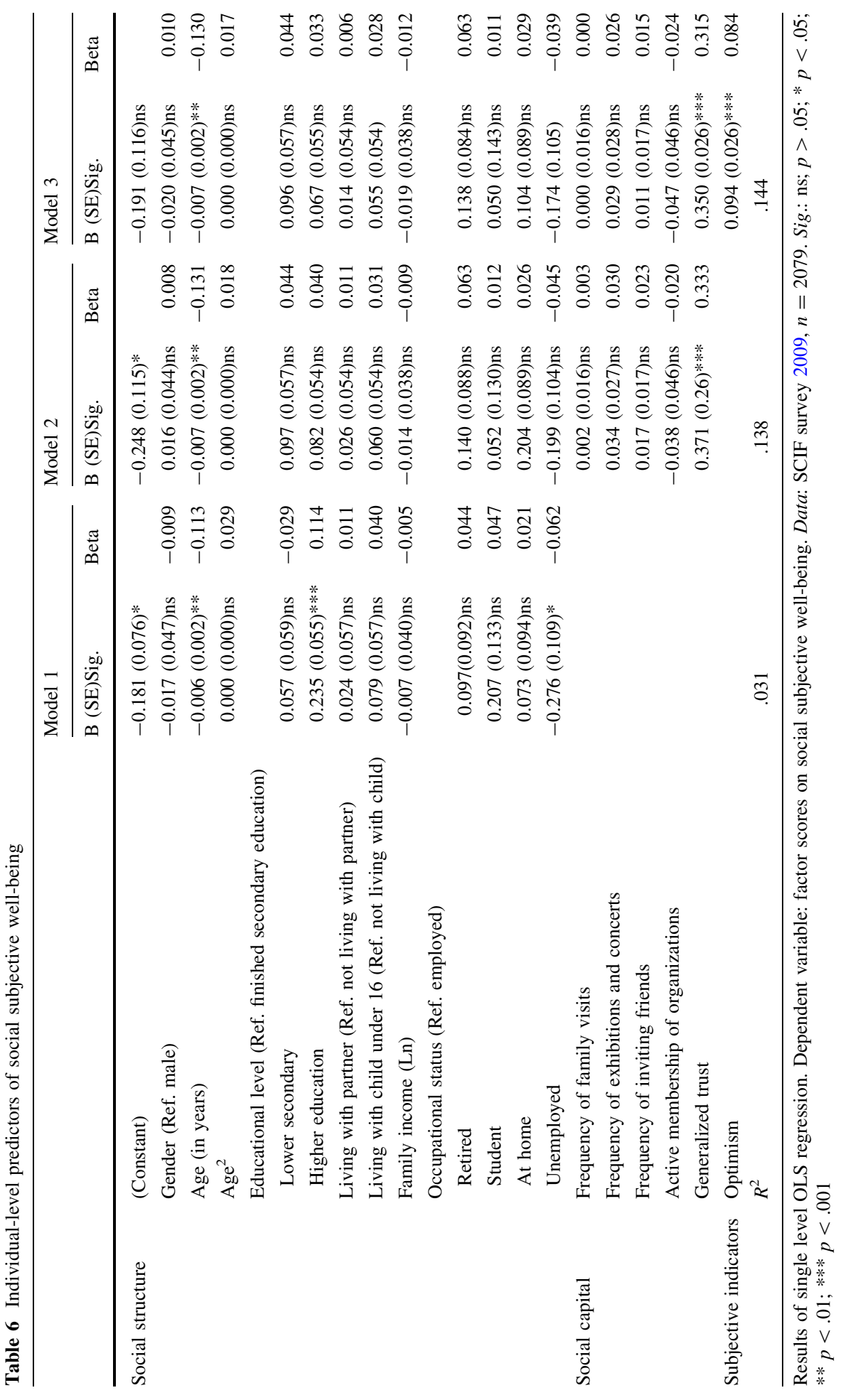


Table 7 The impact of individual and community indicators on general subjective well-being

\begin{tabular}{|c|c|c|}
\hline & $\begin{array}{l}\text { SCIF (Flemish region) } \\
\text { B (SE)Sign. }\end{array}$ & $\begin{array}{l}\text { ESS (Belgium) } \\
\text { B (SE)Sign. }\end{array}$ \\
\hline (Constant) & $6.990(0.192)^{* * *}$ & $6.195(0.560)^{* * *}$ \\
\hline \multicolumn{3}{|l|}{ Level 1: Individual } \\
\hline Gender (Ref. male) & $0.032(0.068) \mathrm{ns}$ & $-0.267(.084)^{* *}$ \\
\hline Age (in years) & $-.006(0.004) \mathrm{ns}$ & $-0.005(.004) \mathrm{ns}$ \\
\hline $\mathrm{Age}^{2}$ & $0.001(0.0002)^{* * *}$ & $0.0002(.0002) \mathrm{ns}$ \\
\hline \multicolumn{3}{|l|}{ Educational level (Ref. finished secondary education) } \\
\hline Lower secondary & $-0.019(0.085) \mathrm{ns}$ & $-0.032(0.103) \mathrm{ns}$ \\
\hline Higher education & $-0.048(0.081) \mathrm{ns}$ & $0.103(0.104) \mathrm{ns}$ \\
\hline Living with partner (Ref. not living with partner) & $0.837(0.116)^{* * *}$ & $0.656(0.105)^{* * *}$ \\
\hline Living with child (Ref. not living with child) & $0.044(0.084) \mathrm{ns}$ & $-0.082(0.100) \mathrm{ns}$ \\
\hline Ln (family income) & $0.180(0.057)^{* *}$ & $0.085(0.070) \mathrm{ns}$ \\
\hline \multicolumn{3}{|l|}{ Occupational status (Ref. employed) } \\
\hline Retired & $-0.113(0.133) \mathrm{ns}$ & $-0.037(0.170) \mathrm{ns}$ \\
\hline Student & $-0.174(0.226) \mathrm{ns}$ & $0.468(0.217)^{*}$ \\
\hline At home & $-0.252(0.135) \mathrm{ns}$ & $-0.253(0.194) \mathrm{ns}$ \\
\hline Unemployed & $-0.439(0.159)^{* *}$ & $-0.264(0.138) \mathrm{ns}$ \\
\hline Frequency of family visits & $0.055(0.025)^{*}$ & $0.109(0.029) * * *$ \\
\hline Frequency of inviting friends & $0.033(.0 .026) \mathrm{ns}$ & \\
\hline Generalized trust & $0.167(0.040)^{* * *}$ & $0.226(0.042) * * *$ \\
\hline Optimism & $0.770(0.086)^{* * *}$ & $0.821(0.077)^{* * *}$ \\
\hline Age*Living with partner & $0.016(0.004)^{* *}$ & \\
\hline Age $^{2} *$ Living with partner & $-0.001(0.0002)^{*}$ & \\
\hline Gender*Optimism & $0.206(0.076)^{* *}$ & $0.210(0.083)^{* *}$ \\
\hline Age*Optimism & $0.009(0.002)^{* * *}$ & \\
\hline Living with partner*Optimism & $-0.481(0.084)^{* * *}$ & $-0.422(0.084)^{* * *}$ \\
\hline \multicolumn{3}{|l|}{ Level 2: Community } \\
\hline Population density $(* 100)$ & $.002(.009) \mathrm{ns}$ & $-0.007(0.003)^{*}$ \\
\hline Violent crime rate & $-.010(.009) \mathrm{ns}$ & $0.022(0.009)^{*}$ \\
\hline Unemployment rate & $-.006(.018) \mathrm{ns}$ & $-0.047(0.009)^{* * *}$ \\
\hline Level 2 variance full model & 0 & 0 \\
\hline Level 1 variance full model & 1.8635 & 2.3955 \\
\hline ICC full model & 0 & 0 \\
\hline Level $1 R^{2}$ full model & .2671 & .2863 \\
\hline Level $2 R^{2}$ full model & 0 & 1 \\
\hline Level 2 variance null model & 0 & 0.1388 \\
\hline Level 1 variance null model & 2.5424 & 3.3566 \\
\hline ICC null model & .0000 & .0397 \\
\hline Number of cases & 1,783 & 1,504 \\
\hline Number of level 2 observations & 40 & 220 \\
\hline
\end{tabular}

Results of a random intercept multilevel analysis of the SCIF survey 2009 and ESS round 3. Dependent variable: item on general life satisfaction. Only significant interactions are included, for each analysis separately. Sign: $* p<.05 ; * * p<.01 ; * * * p<.001$ 
allows us to include both individual and community level independent variables simultaneously in one regression model. To examine the extent of local variation, a null model is first estimated. This model only includes the dependent variable, and it serves as a baseline model to test the variation of the dependent variable on the community level (Snijders and Bosker 1999).

Using the SCIF data, the variation at the community level in our model is absent, with little more than $0 \%$ of all variance that can be attributed to the level of the local community, both for individual as for social subjective well-being. ${ }^{3}$ To make sure that this lack of community level variation is not due to the specific characteristics of the SCIF survey, we also conducted similar separate analyses on the ESS respondents living in the Flemish region. For this control, we used single items on general satisfaction with life and satisfaction with democracy as dependent variables. Including only the Flemish ESS respondents in this analysis, however, led to the same results. We can be quite confident therefore that the lack of intra-class correlation is not caused by some specific characteristics of the SCIF survey but reflects the homogeneity of Flemish communities. While on the individual level, the respondents in this survey differ quite strongly with regard to subjective wellbeing, we do not observe any community differences with regard to individual or social subjective well-being in the Flemish region of Belgium. Models examining variation on the community level for each of the separate domains used in the constructed scales show the same results: even if we take the items of the scale separately, there is hardly any intracommunity correlation of the well-being scores. ${ }^{4}$ One possible explanation for this lack of variation on the level of the communities, is that Flanders is too homogenous, both in cultural and structural terms. Therefore, we also included an analysis on the whole of Belgium, based on the Belgian sample of the ESS.

As was already noted, however, the ESS questionnaire only included the general question on subjective well-being, and therefore we had to rely on this single item. The following analysis therefore is based on the question: "How satisfied are you with your life in general?" As could already be observed in Table 1, however, this single item loads quite strongly on the factor scale, so we can assume that this measurement by itself already includes quite some information on the state of subjective well-being. By restricting the analysis to this item on general subjective well-being, we can use the same dependent variable, both for the Flemish as for the Belgian data, and these data will be used in two different random intercept multilevel models.

The comparison between both analyses suggest that the most important individual level determinants of general subjective well-being are the same in both data sets. Living together with a partner, generalized trust and optimism are confirmed to be strong determinants of subjective well-being measurements. Most importantly, however, is the fact that we observe strong differences on the community level. For the Flemish region by itself, the intra class-correlation at the level of the communities is exactly 0.00 , and therefore there is nothing to be explained at this level. Taking Belgium as a whole, however, yields a modest intra class-correlation of $3.97 \%$, and most of it can be explained by the unemployment rate. It has to be remembered in this regard that the Flemish region is considered as economically successful and in practice is quite homogeneous. In the Flemish region, the average

\footnotetext{
${ }^{3}$ For individual subjective well-being: $\tau=0.00000, \sigma^{2}=0.99952$, ICC $\left(\tau /\left(\tau+\sigma^{2}\right)\right)=0.0000$, sig $=$ 1.000. For social subjective well-being: $\tau=0.00782, \sigma^{2}=0.99181$, ICC $\left(\tau /\left(\tau+\sigma^{2}\right)\right)=0.00782$, sig $=$ 0.054 .

${ }^{4}$ For the other indicators too, intra-class correlation remained extremely limited: satisfaction with leisure time $(0.14 \%)$; with family life $(0.46 \%)$ and sexual life $(0.59 \%)$.
} 
unemployment rate stands at $8 \%$, with a range between 4.6 and $15.1 \%$ of the labor population. Taking Belgium as a whole, however, we obtain an average unemployment rate of $12.4 \%$, ranging between 0 to a maximum of $36 \%$. Including this larger variation, apparently leads to the fact that the unemployment level of the community becomes significant, even when including controls on whether the respondent is unemployed or not.

\section{Discussion}

In this article we examined individual and contextual determinants of subjective well-being in Belgium. On the individual level, our findings confirmed earlier research on the importance of living together with a partner. It is important to note, however, that informal networks (e.g., having friends) and generalized trust remain important determinants of subjective well-being, even after including strong control variables like optimism. Access to social capital, therefore, clearly contributes to a feeling of subjective well-being. Hypotheses 1 and 2 were therefore confirmed for the Belgian context. It is important to note here that all these effects remained significant, even after controlling for a general sense of optimism. We can therefore safely conclude that subjective well-being is not just the reflection of a specific optimistic outlook toward life.

In line with earlier research, we also expected communities to have an impact on subjective well-being and for this reason we used multi-level analysis, including both individual level and community level determinants of subjective well-being. In this multilevel analysis, we see a marked difference between the results for the Flemish region, and for Belgium as a whole. For the rather homogeneous Flemish region, we can observe that there is hardly any intra class-correlation, so we can conclude there are no significant community level determinants of subjective well-being. Using data on Belgium on the other hand, led to significant community influences, mainly of the local unemployment rate. Hypothesis 3 therefore received mixed results: communities matter if the structural indicators differ substantively.

The obvious conclusion therefore is that the region of Flanders simply is too homogeneous, both in cultural and structural terms, to detect strong community effects. ${ }^{5}$ This might explain some of the confounding conclusions that we encountered in the literature on community level effects on subjective well-being. Contextual explanations for the level of subjective well-being have been found in countries with a substantial economic heterogeneity, such as the US, were there are substantial social and economic differences within the population. Income inequality differences in Flanders are quite limited. Crime levels too, tend to be rather low, while the small scale of the region allows for a good distribution of public services across the territory. Real deprived areas in Flanders do exist, of course, but they tend to be rather small and dispersed across the territory. Apparently under these circumstances of homogeneity, community characteristics do not have an impact at all on subjective well-being. It is only if we are able to include regions with much higher levels of unemployment (and these are typically found in Brussels or in the Walloon region), that we find any intra class-correlation on the community level. This suggests some form of

\footnotetext{
5 We have to add here that Belgium is usually considered as a 'diverse society'. Linguistic segregation policies, however, imply that the Flemish region that we investigated in homogenously Dutch speaking, while the Walloon region in the South of the country is homogeneously French speaking. Only in the capital Brussels (ca. 1 million inhabitants) the language groups are not segregated. As such, the region of Flanders can be considered as a homogeneous society, both with regard to language as with regard to income distribution.
} 
threshold model with regard to community impact. One can assume that well-being is lower in extremely poor, crime-ridden, deprived areas. If such a form of segregation and deprivation does not exist, however, apparently marginal differences do not play a role anymore. In a society where all communities reach acceptable levels of material comfort and social cohesion, further gains in standard of living do not seem to have an additional impact on subjective well-being. Our expectation, therefore, is that significant community level determinants of subjective well-being will be found mainly in unequal societies with strong patterns of social and spatial segregation, while the community level might be nonsignificant in more equal or homogeneous societies. Comparative research, including data from different countries, will have to determine whether this expectation is indeed warranted.

\section{References}

Bellah, R. N., Madsen, R., Sullivan, W. M., Swidler, A., \& Tipton, S. M. (1985). Habits of the heart: Individualism and commitment in American life. New York: Harper and Row.

Bjørnskov, C. (2008). Social capital and happiness in the United States. Applied Research in Quality of Life, $3,43-62$.

Blanchflower, D. G. \& Oswald, A. J. (2007) Is well-being U-shaped over the life cycle? The Warwick economics research paper series (TWERPS) 826, University of Warwick, Department of Economics.

Christoph, B., \& Noll, H.-H. (2003). Subjective well-being in the European union during the 90ies. Social Indicators Research, 64, 521-546.

Clark, A. E., \& Oswald, A. J. (1994). Unhappiness and unemployment. Economic Journal, 104, 648-659.

Cummins, R. A. (1995). On the trail of the gold standard for subjective well-being. Social Indicators Research, 35, 179-200.

DeNeve, K., \& Cooper, H. (1998). The happy personality: A meta-analysis of 137 personality traits and subjective well-being. Psychological Bulletin, 124, 197-229.

Di Tella, R., MacCulloch, R. J., \& Oswald, A. J. (2001). Preferences over inflation and unemployment: Evidence from surveys of happiness. American Economic Review, 91, 335-341.

Diener, E. (2000). Subjective well-being - the science of happiness and a proposal for a national index. American Psychologist, 55(1), 34-43.

Diener, E., Diener, M., \& Diener, C. (1995). Factors predicting the subjective well-being of nations. Journal of Personality and Social Psychology, 69, 851-864.

Diener, E., Oishi, S., \& Lucas, R. (2003). Personality, culture, and subjective well-being: Emotional and cognitive evaluations of life. Annual Review of Psychology, 54, 403-425.

Diener, E., Suh, E. M., Lucas, R. E., \& Smith, H. L. (1999). Subjective well-being: Three decades of progress. Psychological Bulletin, 125(2), 276-302.

Dolan, P., Peasgood, T., \& White, M. (2008). Do we really know what makes us happy? A review of the economic literature on the factors associated with subjective well-being. Journal of Economic Psychology, 29(1), 94-122.

Duncan, C., Jones, K., \& Moon, G. (1995). Psychiatric morbidity-a multilevel approach to regional variations in the UK. Journal of Epidemiology and Community Health, 49(3), 290-295.

Easterlin, R. A. (1974). Does economic growth improve the human lot? Some empirical evidence. In P. A. David \& W. R. Melvin (Eds.), Nations and households in economic growth (pp. 98-125). Palo Alto: Stanford University Press.

Easterlin, R. (1995). Will raising the incomes of all increase the happiness of all? Journal of Economic Behavior \& Organization, 27, 35-47.

Eckersley, R. (2009). Population measures of subjective wellbeing: How useful are they? Social Indicators Research, 94(1), 1-12.

Farrell, S., Aubry, T., \& Coulombe, D. (2004). Neighborhoods and neighbors. Do they contribute to personal well-being? Journal of Community Psychology, 32(1), 9-25.

Fernandez, R. M., \& Kulik, J. C. (1981). A multilevel model of life satisfaction: Effects of individual characteristics and neighborhood composition. American Sociological Review, 46(6), 840-850.

Frey, B. S., \& Stutzer, A. (2000). Happiness, economy and institutions. Economic Journal, 110(466), 918938. 
Frey, B. S., \& Stutzer, A. (2002). What can economists learn from happiness research? Journal of Economic Literature, 40(2), 402-435.

Gutierrez, J. L. G., Jimenez, B. M., Hernandez, E. G., \& Puente, C. P. (2005). Personality and subjective well-being: Big five correlates and demographic variables. Personality and Individual Differences, 38(7), 1561-1569.

Hagenaars, A., de Vos, K., \& Zaidi, M. A. (1994). Poverty statistics in the late 1980s: Research based on micro-data. Luxembourg: Office for Official Publications of the European Communities.

Hayes, N., \& Joseph, S. (2003). Big 5 correlates of three measures of subjective well-being. Personality and Individual Differences, 34(4), 723-727.

Helliwell, J. F. (2003). How's life? Combining individual and national variables to explain subjective wellbeing. Economic Modelling, 20(2), 331-360.

Helliwell, J. F., \& Putnam, R. D. (2004). The social context of well-being. Philosophical Transactions of the Royal Society of London Series B-Biological Sciences, 359(1449), 1435-1446.

Hooghe, M., Reeskens, T., Stolle, D., \& Trappers, A. (2009a). Ethnic diversity and generalized trust in Europe. A cross-national multilevel study. Comparative Political Studies, 42(2), 198-223.

Hooghe, M., Vanhoutte, B., \& Bircan, T. (2009b). Technical report for the social cohesion survey Flanders 2009 (SCIF 2009). Leuven: Department of Political Science.

Huppert, F., et al. (2009). Measuring well-being across Europe: Description of the ESS well-being module and preliminary findings. Social Indicators Research, 91(3), 301-315.

Inglehart, R. (1997). Modernization and postmodernization. Princeton: Princeton University Press.

Jowell, R., et al. (2007). ESS 3-2006. Documentation report. London: City University.

Kahneman, D., \& Krueger, A. B. (2006). Developments in the measurement of subjective well-being. Journal of Economic Perspectives, 20(1), 3-24.

Lucas, R. E., Clark, A. E., Georgellis, Y., \& Diener, E. (2003). Reexamining adaptation and the set point model of happiness: Reactions to changes in marital status. Journal of Personality and Social Psychology, 84(3), 527-539.

Lucas, R. E., Diener, E., \& Suh, E. (1996). Discriminant validity of well-being measures. Journal of Personality and Social Psychology, 71(3), 616-628.

Noll, H.-H. (2002). Towards a European system of social indicators. Social Indicators Research, 58(1), $47-$ 88.

Nussbaum, M. (2001). The fragility of goodness. Luck and ethics in Greek tragedy and philosophy. Cambridge: Cambridge University Press.

OECD. (2009). Society at a glance. OECD social indicators. Paris: OECD.

Oswald, A. J. (1997). Happiness and economic performance. Economic Journal, 107(445), 1815-1831.

Plaut, V. C., Markus, H. R., \& Lachman, M. E. (2002). Place matters: Consensual features and regional variation in American well-being and self. Journal of Personality and Social Psychology, 83(1), 160184.

Putnam, R. D. (1993). Making democracy work. Civic traditions in modern Italy. Princeton: Princeton University Press.

Putnam, R. D. (2000). Bowling alone: The collapse and revival of American community. New York: Simon \& Schuster.

Putnam, R. D. (2007). E Pluribus Unum. Diversity and community in the twenty-first century. Scandinavian Political Studies, 30(2), 137-174.

Rahn, W., \& Yoon, K. S. (2009). Geographies of trust. American Behavioral Scientist, 52(12), 1646-1663.

Rampichini, C., \& Schifini d'Andrea, S. (1998). Hierarchical ordinal probit model for the analysis of life satisfaction in Italy. Social Indicators Research, 44(1), 41-69.

Reeskens, T., \& Hooghe, M. (2008). Cross cultural measurement equivalence of generalized trust. Evidence from the European social survey (2002 and 2004). Social Indicators Research, 85(3), 515-532.

Scheier, M. F., \& Carver, C. S. (1985). Optimism, coping, and health: Assessment and implications of generalized outcome expectancies. Health Psychology, 4, 219-247.

Scheier, M. F., Carver, C. S., \& Bridges, M. W. (1994). Distinguishing optimism from neuroticism (and trait anxiety, self-mastery, and self-esteem): A reevaluation of the life orientation test. Journal of Personality and Social Psychology, 67, 1063-1078.

SCIF. (2009). Dataset of the social cohesion indicators survey. Brussels: SCIF.

Snijders, T. A. B., \& Bosker, R. J. (1999). Multilevel analysis: An introduction to basic and advanced multilevel modeling. London: Sage.

Subramanian, S. V., Kim, D., \& Kawachi, I. (2005). Covariation in the socioeconomic determinants of health and happiness: a multilevel analysis of individuals and communities in the USA. Journal of Epidemiology and Community Health, 59, 664-669. 
Suh, E. M. (2000). Self, the hyphen between culture and subjective well-being. In E. Diener \& E. M. Suh (Eds.), Culture and subjective well-being (pp. 63-86). Cambridge: MIT Press.

Veenhoven, R. (1994). Is happiness a trait? Tests of the theory that a better society does not make people any happier. Social Indicators Research, 32(2), 101-160.

Winkelmann, R. (2009). Unemployment, social capital, and subjective well-being. Journal of Happiness Studies, 10(4), 421-430.

Wrosch, C., \& Scheier, M. F. (2003). Personality and quality of life: The importance of optimism and goal adjustment. Quality of Life Research, 12, 59-72. 